Marco Celentani · J. Ignacio Conde-Ruiz

Klaus Desmet

\title{
Inflation in open economies with complete markets
}

\begin{abstract}
This paper uses an overlapping generations model to analyze monetary policy in a two-country model with asymmetric shocks. Agents insure against risk through the exchange of a complete set of real securities. Each central bank is able to commit to the contingent monetary policy rule that maximizes domestic welfare. In an attempt to improve their country's terms of trade of securities, central banks choose to commit to costly inflation in favorable states of nature. In equilibrium the effects on the terms of trade wash out, leaving both countries worse off. Countries facing asymmetric shocks may therefore gain from monetary cooperation.
\end{abstract}

Keywords Inflation $\cdot$ Risk sharing $\cdot$ Security markets $\cdot$ Terms of trade $\cdot$ Monetary cooperation $\cdot$ Currency union

We are indebted to an anonymous referee, Pedro Alvarez-Lois, Subir Chattopadhyay, Jordi Galí, Berthold Herrendorf, Tommaso Monacelli, Ignacio Ortuño, Javier Vallés, and especially Ronald McKinnon for helpful comments and discussions. We acknowledge the financial support of Fundación BBVA, the Ministry of Science and Technology (BEC 2002-03715), the Comunidad de Madrid (06/0096/03), and the Commission for Cultural, Educational and Scientific Exchange between the United States of America and Spain (Project 7-42). Much of this research was carried out while Klaus Desmet was visiting the Bank of Spain and Stanford University, and he wishes to thank the hospitality of both institutions. The views expressed are those of the authors and not necessarily those of the Spanish Prime Minister's Bureau.

M. Celentani $(\varangle)$

Department of Economics, Universidad Carlos III, Getafe (Madrid) 28903, Spain

E-mail: marco.celentani@uc3m.es

\section{J. I. Conde-Ruiz}

Spanish Prime Minister Economic Bureau and FEDEA,

Presidencia del Gobierno, Complejo de la Moncloa, 28071 Madrid, Spain

E-mail: jiconde@presidencia.gob.es

\section{K. Desmet}

Department of Economics, Universidad Carlos III and CEPR, Getafe (Madrid) 28903, Spain

E-mail: klaus.desmet@uc3m.es 
JEL Classification Numbers E5 - F3 · F42

\section{Introduction}

It is well known that separate currencies may lead to inefficient risk sharing between countries (Mundell 1961; McKinnon 2002). Consider, for instance, a two-country world with asymmetric shocks, in which agents diversify risk by trading in a complete set of nominal contingent securities. In such an environment central banks have an incentive to create ex post-surprise inflation whenever their country has payments due. Of course, those policies end up backfiring under rational expectations (Barro and Gordon 1983a,b). Once agents understand the incentives of central banks, inflation ceases to come as a surprise, leaving the economy with the worst of two worlds: the benefits of inflation vanish, while its costs persist.

If central banks were able to unilaterally commit to a contingent monetary policy rule, we would expect this inflationary bias to disappear, thus ensuring efficient risk sharing. Under a contingent policy rule, the real value of nominal contingent securities becomes known in advance, eliminating any role for unexpected inflation. In as far as actual inflation continues to be costly, it would then seem that the optimal policy rule-if credibly implementable-should prescribe price stability.

This paper shows that this intuition is erroneous: in spite of eliminating the possibility of affecting the real value of nominal payments, unilateral commitment is not enough to avoid excess inflation and to guarantee efficient risk sharing. To make our point as stark as possible, we will assume that agents trade in a complete set of indexed nominal-i.e., real - securities. By doing so, it should be doubly clear that the inefficiencies we describe are not due to central banks inflating away the value of nominal claims, but to a different mechanism.

Our model has the following characteristics. There are two countries. In each period, each country is populated by a unit mass of old and a unit mass of young. The young of each country receive an endowment of the same unique commodity, but derive no utility from consumption. The old of each country receive no endowment, but want to consume. Money, which is in the hands of the old, allows for welfare enhancing intergenerational trade. Countries face perfectly negatively correlated asymmetric shocks to the endowments of the young. There are two states of nature. For each state there exists a corresponding indexed nominal security that delivers the monetary equivalent of one unit of the commodity in that state. To insure themselves against consumption risk, the old of both countries trade in those securities.

The timing is as follows. At the beginning of each period, each central bank unilaterally commits to the contingent policy rule that maximizes domestic welfare. The old from the two countries then share consumption risk by trading indexed nominal contingent securities. Once the state of nature is revealed, the monetary policy is implemented, the securities are redeemed, the old buy the endowment from the young, and consume. Goods prices adjust to changes in the money supply, though inflation is costly. When buying the endowment, the old pass on their money holding to the young, so that by the beginning of the next period the (by then) old hold the entire money stock.

The first result is that under unilateral commitment central banks will use inflation to manipulate the terms of trade of the indexed nominal securities. The intuition 
is easy to understand. The old residents of a given country are net suppliers of the security that makes a payment in the state of nature favorable to their country's young. Their central banks may then find it optimal to commit to positive inflation in that state. Since costly inflation lowers the endowment of the young-and therefore the consumption of the old - the country's old residents become less willing to supply the security they are a net supplier of, thus pushing up its relative price. If the ex ante welfare gain from the relative price increase more than compensates the cost of inflation, central banks optimally choose to commit to strictly positive inflation in the favorable state.

The second result is that efficient risk sharing requires monetary cooperation. Under unilateral commitment both central banks create inflation in an attempt to improve their terms of trade. In a symmetric setting, the Nash equilibrium of the non-cooperative game leaves everyone worse off compared to the case of monetary stability. The positive effects on the terms of trade of securities wash out, while leaving each country with the cost of inflation. To reach the optimal outcome, some form of cooperation is necessary, either through negotiations between two separate central banks, or through a full-blown currency union.

The third result suggests that our findings go through when we deviate from symmetry. As soon as we introduce asymmetries - for instance, in the sizes of countries - the optimal level of inflation differs across countries, so that the effects on the relative price of securities cease to cancel each other out. As a result, one of the two countries now benefits from an ex post-improvement in its terms of trade. If that gain is big enough to compensate for the loss from inflation, the non-cooperative Nash equilibrium makes that country better off compared to a situation of price stability. Even in that case, however, cooperation typically leads to a Pareto superior outcome with lower inflation.

The existing literature on monetary policy in open economies emphasizes that unanticipated inflation can be beneficial when there are nominal rigidities. An example is Corsetti and Pesenti (2001) who consider a model with monopolistically competitive firms and sticky wages. In that setup an unexpected inflationary shock increases output and improves efficiency. However, it has the negative effect of depressing the terms of trade of exportables. In equilibrium inflation may be positive, though the incentive to inflate is lower in an open economy than in a closed economy.

In contrast, our paper focuses on anticipated inflation. As a further difference, we find the inflationary bias to be specific to an open economy. For our result to hold, the only assumption we need is that anticipated inflation is costly. It does not matter where exactly this cost comes from. Nominal rigidities is a possible explanation. However, inflation could also be costly for a variety of other reasons: inflation makes agents "substitute away from activities that require cash, such as consumption, for activities that do not require cash, such as leisure" (Cooley and Hansen 2001); inflation induces a switch to costly trade transactions to avoid the inflation tax (Gillman 1993); inflation harms other nominally denominated means of exchanges such as credit (Ferraris 2005); and inflation can be used to finance inefficient government spending. In this paper we explicitly choose to be silent about the microeconomic source of the inflation cost. By doing so, we want to make clear that our result only relies on anticipated inflation being costly, but not on the specific nature of that cost. 
Closer in spirit to our work is Cooley and Quadrini (2003), who deviate from the "new open-economy macroeconomic" literature by considering perfectly competitive markets and flexible prices. In a two-country production economy firms use local and imported intermediate goods to produce final goods. The purchase of intermediate goods has to be financed by nominal loans. Although higher interest rates increase the financing cost, they also have the benefit of reducing the demand for importables, thus pushing up the country's terms of trade in intermediate goods. In contrast to Corsetti and Pesenti (2001) they conclude that open economies lead to an inflationary bias. What sets our model apart is that, unlike Cooley and Quadrini (2003), we focus on uncertainty and the role of security markets. We analyze the response of inflation to aggregate shocks, and find that inflation is procyclical.

Since Mundell (1961), the rule-of-thumb has been that countries should keep separate currencies if they face asymmetric shocks and labor is immobile across countries. Our paper says the opposite: it is exactly when countries face asymmetric shocks that they benefit most from risk sharing, making the payoff from adopting a common currency greatest. This argument has been made before by Mundell (1961), and more recently, by McKinnon (2002) and Ching and Devereux (2000, 2003). However, in contrast to that literature, we show that monetary cooperation may be beneficial even if individual central banks have the ability to unilaterally commit to optimal monetary policies.

At a general level our paper argues that inflation may arise in equilibrium, even in a perfectly competitive framework with complete markets, flexible prices, and central banks committing to contingent monetary policy rules. In that sense our work is related to Kurz et al. (2003) who demonstrate that monetary policy may have non-neutral effects in a competitive framework with flexible prices. Building on the notion of rational beliefs, introduced by Kurz (1994), they show that it is enough for agents to hold heterogeneous beliefs about state variables for central banks to have an incentive to create inflation.

\section{Setup of the model}

\subsection{Building blocks of the model}

The basic setup of the model is an overlapping generations version of Celentani et al. (2004). Consider two countries, West and East. In each period, each country is populated by a unit mass of homogeneous old and a unit mass of homogeneous young. There is only one commodity, ${ }^{1}$ which is non-storable and freely transportable.

When young, agents in the West and the East receive an endowment of the unique commodity, but derive no utility from consumption. The economy's total endowment is 2 . Although there is no aggregate uncertainty, countries are subject to perfectly negatively correlated shocks of size $\alpha$, where $0<\alpha<1$. This gives us two states of nature: in state $s=\omega$ the young in the West get an endowment $1+\alpha$ whereas the young in the East get $1-\alpha$; in state $s=\varepsilon$ the young in the

\footnotetext{
1 This rules out shocks to the relative price of exportables.
} 
West receive endowment $1-\alpha$ whereas the young in the East receive $1+\alpha$. In the symmetric case, each state occurs with probability $1 / 2 .^{2}$

When old, agents receive no endowment, but derive utility from consumption. Agents are risk averse. To keep the problem analytically tractable, we focus on CRRA preferences, so that the expected utilities of the old can be written as:

$$
\begin{array}{r}
\mathcal{W}\left(c_{\omega}^{\mathrm{W}}, c_{\varepsilon}^{\mathrm{W}}\right)=\frac{1}{2} \frac{\left(c_{\omega}^{\mathrm{W}}\right)^{1-\rho}}{1-\rho}+\frac{1}{2} \frac{\left(c_{\varepsilon}^{\mathrm{W}}\right)^{1-\rho}}{1-\rho}, \\
\mathcal{E}\left(c_{\omega}^{\mathrm{E}}, c_{\varepsilon}^{\mathrm{E}}\right)=\frac{1}{2} \frac{\left(c_{\omega}^{\mathrm{E}}\right)^{1-\rho}}{1-\rho}+\frac{1}{2} \frac{\left(c_{\varepsilon}^{\mathrm{E}}\right)^{1-\rho}}{1-\rho},
\end{array}
$$

where $\rho$ is the coefficient of relative risk aversion (where $\rho>0$ ), and $c_{s}^{\mathrm{i}}$ denotes state $s$ consumption of an old agent in country $\mathrm{i}=\mathrm{E}, \mathrm{W}$.

In this environment, in which the old want to consume but have no endowment, and the young have an endowment but do not want to consume, money allows for welfare enhancing intergenerational trade. Assume that at the beginning of any period the old of each country hold all the local currency. Furthermore assume that when buying goods from the young in a given country, the old must pay in the local currency. By setting the money supply, central banks determine the price level. For instance, if a central bank creates a money supply $M$, and the country's endowment is $Q$, then applying the quantity equation of money gives us a price level $M / Q .^{3}$ To increase the money supply, newly issued money is costlessly distributed to the old; to decrease money supply, part of the old's money is costlessly confiscated.

Given the existence of asymmetric shocks, there is obvious room for risk sharing. To insure risk, the old of the two countries trade in two indexed nominal contingent securities, each paying the monetary equivalent of one unit of endowment in one state of nature and zero in the other. In particular, security $\omega$ pays out in state $\omega$ a number of units of the West's currency sufficient to purchase one unit of the commodity; likewise, security $\varepsilon$ pays out in state $\varepsilon$ a number of units of the East's currency sufficient to purchase one unit of the commodity. Needless to say, these indexed nominal securities are equivalent to real securities ${ }^{4}$ and they are sufficient to complete markets.

Inflation decreases the endowment, though we are largely agnostic as to why this is so. To keeps things simple, we assume that an inflation rate of $\pi$ reduces the economy's endowment by $\delta \pi Q$, with $\pi \in[0,1 / \delta]^{5}$

The goal of this paper is to study monetary policy rules under unilateral commitment. To ensure that our results are not driven by restrictions on policy sets, we assume that central banks can commit to contingent monetary policies. This means that each central bank commits to contingent inflation rates, one for each

\footnotetext{
${ }^{2}$ We will later discuss different forms of asymmetries between countries.

${ }^{3}$ We assume a velocity of money of 1 , since a period in this model does not have an explicit duration.

${ }^{4}$ See Magill and Quinzii (1996, chapter 7). We prefer to focus on indexed nominal securities, though, because the modeling is slightly more elegant, and because it seems more natural in a monetary model to think of contracts delivering the monetary equivalent of physical goods, rather than the physical goods themselves. We will return to this issue in section 3.1.

5 As in Alesina and Barro (2002) the cost is increasing in the rate of inflation and proportional to the economy's endowment.
} 
state. Though this introduces uncertainty in policy realization, it does not introduce policy risk, because we consider pure strategy equilibria in which each central bank chooses a conditional policy with probability 1 . This means that no security is needed to hedge against policy risk (because there is none). Securities $\omega$ and $\varepsilon$ are sufficient to complete markets because they allow individual agents to hedge against the realization of the aggregate state and the resulting realization of policies.

Since only the old consume, a country's welfare is measured by the utility of its old. Each central bank sets contingent inflation rates to maximize the welfare of its old, taking the policy of the other central bank as given. The policy rules therefore correspond to the pure strategy Nash equilibrium of the non-cooperative game between the two central banks. Note that by endowing the monetary authorities with the ability to commit, we assume away credibility problems. It is well known that policy rules may be dynamically inconsistent if the benefit from deviating is greater than its cost. However, since this paper aims to show that there are other reasons that may lead to suboptimal inflation rates, we abstract from these issues.

To understand the mechanics of the model, it is important to be clear about the sequencing of events in each period:

1. Central banks simultaneously and independently commit to contingent monetary policy rules.

2. The old from both countries exchange indexed nominal securities.

3. The state of nature is revealed. Central banks set the money supply in accordance with the inflation level they committed to.

4. Indexed nominal securities are redeemed.

5. The old spend all their money holdings to buy up the endowment (net of inflation costs) from the young.

It is now easy to see how at the beginning of each period the old end up with all of the local currency. Since at the end of each period the old use their money holdings to buy up the endowment from the young, and since goods are paid for in the local currency, the young receive all the currency of their respective countries. At the beginning of the next period, therefore, the (by then) old of each country hold the entire stock of local currency. Note, furthermore, that all periods are identical: since agents only consume when they are old and since goods are non-storable, there is no intertemporal trade. For the rest of the paper it will therefore suffice to focus on just one period.

\subsection{Discussion of the model}

Although in our model unilateral commitment implies that realized inflation is always perfectly anticipated, we will see that central banks still choose policy rules that deviate from price stability in an attempt to improve the terms of trade of indexed nominal securities. In the framework of our stylized model this possibility of tinkering with the relative prices of securities depends on the ability of each central bank to commit to monetary policy before agents trade securities. This assumption is justified for two reasons.

First, each central bank finds it individually optimal to decide contingent inflation rates in advance. By setting monetary policy upfront, a central bank can manipulate the terms of trade of securities to its benefit; if, instead, it were to 
set monetary policy after observing the state of nature, it would give up this possibility. In other words, if we were to allow central banks to choose whether to set inflation rates before or after securities trade, they would set them before securities trade. In this sense the timing we focus on is a reflection of individual optimality on the part of each central bank.

Second, in a more general dynamic model with sequentially complete markets and agents living multiple periods, our result would go through, independently of when central banks choose their monetary policy rules. In sequentially complete markets trading happens at different dates. Therefore, as long as central banks commit to contingent monetary policy rules for a time span during which individuals need to trade securities to hedge risk, the possibility of manipulating security prices continues to exist. The intuition is the following: with sequentially complete markets, no matter when a central bank decides on its policy rule, it will always be before some future security trade, thus allowing the central bank to affect future security prices. The specific timing we adopt should therefore be interpreted as a convenient way of driving home the result in a stripped down one period setting, but it would not be essential in a richer setting. For a related discussion, refer to Celentani et al. (2004) .

\section{Monetary policy under unilateral commitment}

In this section we derive the equilibrium of the monetary policy game described above. We solve the model backwards. First we determine the security market equilibrium for given monetary policy rules. Then we move to the previous stage in which central banks simultaneously and independently choose the policy rules. Central banks understand how their decisions translate into securities prices and trades, and eventually into expected utilities. In the Nash equilibrium of this game, each central bank maximizes the welfare of its old, taking the monetary policy of the other central bank as given.

\subsection{The second stage: solving for the security market equilibrium}

We start by looking at the optimization problem of the representative old agent in the West for given monetary policy rules in both countries. Let $x_{s}^{\mathrm{W}}$ be his purchase - or sale, if $x_{s}^{\mathrm{W}}$ is a negative number - of nominal indexed security $s=\omega, \varepsilon$. To simplify the optimization expression, note that a central bank's incentive to commit to strictly positive inflation only exists in that state of nature in which its country experiences a favorable shock. Committing to strictly positive inflation in the unfavorable state is clearly dominated by committing to zero inflation. Indeed, costly inflation in the unfavorable state would push up the country's demand for the security it is already a demander of. As a result, the price of that security would increase, amounting to a worsening in the country's terms of trade. This implies that in equilibrium $\pi_{\varepsilon}^{\mathrm{W}}=\pi_{\omega}^{\mathrm{E}}=0$.

The net demand for securities by the representative old agent in the West, $\left(x_{\omega}^{W}, x_{\varepsilon}^{W}\right)$, can thus be derived as the solution to the following maximization problem: 


$$
\begin{aligned}
\max _{x_{\omega}^{\mathrm{W}}, x_{\varepsilon}^{\mathrm{W}}} & \frac{1}{2} \frac{\left((1+\alpha)\left(1-\delta \pi_{\omega}^{\mathrm{W}}\right)+x_{\omega}^{\mathrm{W}}\right)^{1-\rho}}{1-\rho}+\frac{1}{2} \frac{\left(1-\alpha+x_{\varepsilon}^{\mathrm{W}}\right)^{1-\rho}}{1-\rho}, \\
\text { s.t. } & x_{\omega}^{\mathrm{W}}+p x_{\varepsilon}^{\mathrm{W}}=0,
\end{aligned}
$$

where $p$ is the price of security $\varepsilon$ relative to the price of security $\omega$. We refer to $p$ as the East's terms of trade in securities (and to $1 / p$ as the West's terms of trade in securities). Although indexed nominal securities and real securities are equivalent in that the value of neither can be inflated away, there is a slight difference in how they would show up in equation (3). To see this, remember that the cost of inflation is a proportion of all commodities bought with money. If, as in (3), we use nominal indexed securities, delivering the monetary equivalent of physical goods, the inflation cost is a proportion of the country's entire endowment. If, instead, we were to use real securities, delivering physical goods, the inflation cost would only be a proportion of the country's endowment net of securities. The qualitative results would not change though, since the only crucial element in our model is that inflation has a negative welfare effect. We prefer to focus on indexed nominal securities because the algebra is slightly more elegant. Moreover, as pointed out by Magill and Quinzii (1996), in a monetary model it seems more natural to think of contracts delivering the monetary equivalent of real goods.

Likewise, the net demand for securities by the representative old agent in the East, $\left(x_{\omega}^{\mathrm{E}}, x_{\varepsilon}^{\mathrm{E}}\right)$, can be derived as the solution to the following maximization problem:

$$
\begin{aligned}
\max _{x_{\omega}^{\mathrm{E}}, x_{\varepsilon}^{\mathrm{E}}} & \frac{1}{2} \frac{\left(1-\alpha+x_{\omega}^{\mathrm{E}}\right)^{1-\rho}}{1-\rho}+\frac{1}{2} \frac{\left((1+\alpha)\left(1-\delta \pi_{\varepsilon}^{\mathrm{E}}\right)+x_{\varepsilon}^{\mathrm{E}}\right)^{1-\rho}}{1-\rho}, \\
\text { s.t. } & x_{\omega}^{\mathrm{E}}+p x_{\varepsilon}^{\mathrm{E}}=0 .
\end{aligned}
$$

Market clearing requires that:

$$
x_{s}^{\mathrm{E}}=-x_{s}^{\mathrm{W}}, \quad s=\omega, \varepsilon .
$$

From (3), (4), and (5), we obtain the equilibrium quantities of securities demanded and supplied:

$$
\begin{gathered}
x_{\omega}^{\mathrm{W}}\left(\pi_{\omega}^{\mathrm{W}}, \pi_{\varepsilon}^{\mathrm{E}}, \widehat{p}\right)=\frac{(1-\alpha) \widehat{p}-(1+\alpha)\left(1-\delta \pi_{\omega}^{\mathrm{W}}\right) \widehat{p}^{(\rho-1) / \rho}}{\widehat{p}^{(\rho-1) / \rho}+1}, \\
x_{\varepsilon}^{\mathrm{E}}\left(\pi_{\omega}^{\mathrm{W}}, \pi_{\varepsilon}^{\mathrm{E}}, \widehat{p}\right)=\frac{(1+\alpha)\left(1-\delta \pi_{\omega}^{\mathrm{W}}\right) \widehat{p}^{-1 / \rho}-(1-\alpha)}{\widehat{p}^{(\rho-1) / \rho}+1}, \\
x_{\omega}^{\mathrm{E}}\left(\pi_{\omega}^{\mathrm{W}}, \pi_{\varepsilon}^{\mathrm{E}}, \widehat{p}\right)=\frac{(1+\alpha)\left(1-\delta \pi_{\varepsilon}^{\mathrm{E}}\right) \widehat{p}-(1-\alpha) \widehat{p}^{(\rho-1) / \rho}}{\widehat{p}^{(\rho-1) / \rho}+1}, \\
x_{\varepsilon}^{\mathrm{E}}\left(\pi_{\omega}^{\mathrm{W}}, \pi_{\varepsilon}^{\mathrm{E}}, \widehat{p}\right)=\frac{(1-\alpha) \widehat{p}^{-1 / \rho}-(1+\alpha)\left(1-\delta \pi_{\varepsilon}^{\mathrm{E}}\right)}{\widehat{p}^{(\rho-1) / \rho}+1},
\end{gathered}
$$


where $\widehat{p}$ is given by:

$$
\widehat{p}\left(\pi_{\omega}^{\mathrm{W}}, \pi_{\varepsilon}^{\mathrm{E}}\right)=\left(\frac{(1+\alpha)\left(1-\delta \pi_{\omega}^{\mathrm{W}}\right)+(1-\alpha)}{(1+\alpha)\left(1-\delta \pi_{\varepsilon}^{\mathrm{E}}\right)+(1-\alpha)}\right)^{\rho} .
$$

Notice that $\widehat{p}$ is a function of $\pi_{\omega}^{\mathrm{W}}$ and $\pi_{\varepsilon}^{\mathrm{E}}$. By substituting (10) into (6)-(9) we can therefore write equilibrium net demands of securities as functions of the inflation rates: $\widehat{x}_{s}^{\mathrm{i}}\left(\pi_{\omega}^{\mathrm{W}}, \pi_{\varepsilon}^{\mathrm{E}}\right), \mathrm{i}=\mathrm{E}, \mathrm{W}, s=\omega, \varepsilon$.

\subsection{The first stage: solving for the optimal policy rules}

Now that we have characterized how equilibrium net demands of securities depend on inflation rates, we can move back to the previous stage and derive the monetary policy rules. Given that each central bank commits to the monetary policy rule that maximizes the ex ante welfare of its old, the best response of the West's central bank to a given monetary policy of the East, $\pi_{\varepsilon}^{E}$, is the solution to: ${ }^{6}$

$$
\begin{aligned}
& \max _{\pi_{\omega}^{\mathrm{W}}} \mathcal{W}\left(\pi_{\omega}^{\mathrm{W}}, \pi_{\varepsilon}^{\mathrm{E}}\right)= \frac{1}{2} \frac{\left((1+\alpha)\left(1-\delta \pi_{\omega}^{\mathrm{W}}\right)+\widehat{x}_{\omega}^{\mathrm{W}}\left(\pi_{\omega}^{\mathrm{W}}, \pi_{\varepsilon}^{\mathrm{E}}\right)\right)^{1-\rho}}{1-\rho} \\
&+\frac{1}{2} \frac{\left(1-\alpha+\widehat{x}_{\varepsilon}^{\mathrm{W}}\left(\pi_{\omega}^{\mathrm{W}}, \pi_{\varepsilon}^{\mathrm{E}}\right)\right)^{1-\rho}}{1-\rho}, \\
& \text { s.t. } \quad 0 \leq \pi_{\omega}^{\mathrm{W}} \leq \frac{1}{\delta} .
\end{aligned}
$$

Note that we are restricting inflation to be weakly positive. ${ }^{7}$ In a similar way, the best response of the East's central bank to a given monetary policy of the West, $\pi_{\omega}^{\mathrm{W}}$, is the solution to the following maximization problem:

$$
\begin{aligned}
& \max _{\pi_{\varepsilon}^{\mathrm{E}}} \mathcal{E}\left(\pi_{\omega}^{\mathrm{W}}, \pi_{\varepsilon}^{\mathrm{E}}\right)= \frac{1}{2} \frac{\left(1-\alpha+\widehat{x}_{\omega}^{\mathrm{E}}\left(\pi_{\omega}^{\mathrm{W}}, \pi_{\varepsilon}^{\mathrm{E}}\right)\right)^{1-\rho}}{1-\rho} \\
&+\frac{1}{2} \frac{\left((1+\alpha)\left(1-\delta \pi_{\varepsilon}^{\mathrm{E}}\right)+\widehat{x}_{\varepsilon}^{\mathrm{E}}\left(\pi_{\omega}^{\mathrm{W}}, \pi_{\varepsilon}^{\mathrm{E}}\right)\right)^{1-\rho}}{1-\rho}, \\
& \text { s.t. } \quad 0 \leq \pi_{\varepsilon}^{\mathrm{E}} \leq \frac{1}{\delta} .
\end{aligned}
$$

The first order conditions to problems (11) and (12) give the best responses of the central banks and their intersection gives the Nash equilibrium inflation rates.

Before deriving the first order conditions, note from (11) and (12) that inflation affects the demand and supply - and thus the price - of securities. Central banks

\footnotetext{
${ }^{6}$ Recall that we have argued that in equilibrium $\pi_{\varepsilon}^{\mathrm{W}}=\pi_{\omega}^{\mathrm{E}}=0$ because setting a strictly positive value for $\pi_{\varepsilon}^{\mathrm{W}}\left(\pi_{\omega}^{\mathrm{E}}\right)$ is dominated for the central bank of the West (East) by setting $\pi_{\varepsilon}^{\mathrm{W}}=0\left(\pi_{\omega}^{\mathrm{E}}=0\right)$. For this reason we can simplify notation by restricting attention to the inflation rates set by central banks for the states of nature favorable to their respective residents, i.e., $\pi_{\omega}^{W}$ and $\pi_{\varepsilon}^{\mathrm{E}}$.

${ }^{7}$ If the cost of inflation is interpreted as menu cost, one could of course argue that inflation and deflation have the same effects. In that case, the incentive to create inflation would more generally become an incentive to create price instability.
} 
can therefore use monetary policy to improve the terms of trade of securities. In particular, a central bank may have an incentive to commit to strictly positive inflation for the state in which its country experiences a favorable shock. The argument runs as follows. Inflation in a given state $s$ lowers the endowment of the country's young. This smaller endowment reduces what the country's old can consume, making them less willing to supply security $s$. This pushes up the security's price. If this price increase happens in the state in which the country receives a positive shock, then the country experiences an improvement in its terms of trade, because in that state the country's old are net suppliers of the security. Then, if the indirect (positive) effect of higher relative prices dominates the direct (negative) effect of a smaller endowment, the central bank finds it optimal to commit to a strictly positive level of inflation for that state.

If an interior solution exists, the marginal cost of creating inflation must equal the marginal benefit. This is reflected in the first order conditions of (11) and (12):

$$
(1+\alpha) \delta=\frac{x_{\omega}^{\mathrm{W}}}{\widehat{p}} \frac{\partial \widehat{p}}{\partial \pi_{\omega}^{\mathrm{W}}}
$$

and

$$
(1+\alpha) \delta=-\frac{x_{\varepsilon}^{\mathrm{E}}}{\widehat{p}} \frac{\partial \widehat{p}}{\partial \pi_{\varepsilon}^{\mathrm{E}}}
$$

The marginal cost of inflation - the left hand side in (13) and (14) - amounts to the fraction $\delta$ of the endowment lost due to inflation costs. The marginal benefit of inflation - the right hand side in (13) and (14) - corresponds to the marginal proportional improvement in the terms of trade of securities multiplied by the demand.

The following proposition derives the Nash equilibrium.

Proposition 1 In the unique pure strategy Nash equilibrium of the symmetric game,

1. If $\alpha \rho>2$,

$$
\widehat{\pi}_{\omega}^{W}=\widehat{\pi}_{\varepsilon}^{E}=\frac{2 \alpha \rho-4}{(1+\alpha) \delta(\rho-2)} .
$$

If $\alpha \rho<2$,

$$
\widehat{\pi}_{\omega}^{W}=\widehat{\pi}_{\varepsilon}^{E}=0
$$

2. If $\alpha \rho>2$,

$$
\begin{aligned}
& \frac{\partial \widehat{\pi}_{\omega}^{W}}{\partial \rho}=\frac{\partial \widehat{\pi}_{\varepsilon}^{E}}{\partial \rho}=\frac{(1+\alpha)(4(1-\alpha))}{((1+\alpha) \delta(\rho-2))^{2}}>0, \\
& \frac{\partial \widehat{\pi}_{\omega}^{W}}{\partial \alpha}=\frac{\partial \widehat{\pi}_{\varepsilon}^{E}}{\partial \alpha}=\frac{(\rho-2)(2 \rho+4) \delta}{((1+\alpha) \delta(\rho-2))^{2}}>0 .
\end{aligned}
$$


Proof See Appendix A.1.

Proposition 1 indicates that equilibrium inflation is higher when risk aversion, $\rho$, is higher. With greater risk aversion the demand for securities is more inelastic, so that a reduction in supply has a bigger impact on the relative prices. Put differently, when risk aversion is higher, the marginal benefit of inflation in the favorable state is greater, and this translates into higher equilibrium inflation.

Proposition 1 also establishes that when the size of the shock, $\alpha$, increases, equilibrium inflation goes up. There are two reasons for this. First, inflating in the favorable state entails a cost which is measured by the marginal disutility of reducing consumption in that state. When the size of the (positive) shock is larger, decreasing marginal utility implies that this cost is lower. Second, inflating in the favorable state produces a benefit that is measured by the marginal utility of the increase in consumption in the unfavorable state because of the improvement in the terms of trade. When the size of the (negative) shock is larger, decreasing marginal utility implies that this benefit is higher.

Notice that according to Proposition 1 equilibrium inflation is positive only when $\alpha$ and/or $\rho$ are sufficiently high. We have already explained why higher values of $\alpha$ and/or $\rho$ generate higher inflation levels. As for the corner solutions at low values of $\alpha$ and $\rho$, they should be viewed as an artifact of the simplicity of the model. In particular, if consumer preferences were to include public goods financed by seigniorage, the incentive to create inflation would be much greater.

Furthermore remark that the parameter measuring the marginal cost of inflation, $\delta$, does not affect the condition for an interior solution. The reason is that each central bank optimizes the reduction in its country's endowment. Since the drop in the endowment depends on $\delta \pi$, a higher $\delta$ simply leads to a lower $\pi$, leaving $\delta \pi$ unchanged. As a result, whether optimal inflation is strictly positive or not does not depend on $\delta$.

As both central banks individually strive to manipulate the relative prices of securities to their benefit, symmetry implies that in equilibrium the old residents of both countries end up worse off. The following proposition summarizes this insight.

Proposition 2 In the pure strategy Nash equilibrium of the symmetric game, if $\alpha \rho>2$,

1. The relative price of nominal indexed securities is 1 .

2. The allocation is inefficient.

\section{Proof See Appendix A.2.}

These results are intuitive. If countries are symmetric, their attempts at using inflation to improve the terms of trade of their securities cancel each other out completely. Note also that, since in each state of nature one of the two countries creates inflation, and since that level of inflation is identical, the aggregate endowment net of the losses from inflation remains constant across states of nature. This implies that equilibrium trades allow the old to fully smooth consumption. But the equilibrium allocation is inefficient, because creating inflation is equivalent to decreasing the endowment. This makes both countries worse off compared to a situation of price stability, as both suffer the negative welfare effects of inflation, while neither benefits from an improvement in the terms of trade at which they obtain insurance. 
The simplicity of our model generates an artificial asymmetry. A central bank commits to positive inflation whenever shocks are positive, but to zero inflation, rather than deflation, whenever shocks are negative. This outcome is specific to our endowment economy, since a central bank can reduce, but never increase, its country's endowment. In a full-fledged OLG model with production and endogenous labor supply, this asymmetry would disappear. Since a central bank would have the possibility to both decrease and increase labor supply, it would commit to inflation whenever shocks are positive, and to deflation whenever shocks are negative. The results for our endowment economy are qualitatively the same though, in that the equilibrium is suboptimal and inflation is procyclical.

Note that reversing the timing, with central banks deciding monetary policy in a discretionary way after observing the economy's state of nature, would improve welfare in both countries. Indeed, since agents can trade in a full set of nominal indexed securities, central banks would find no benefit in creating inflation ex post. The result would be price stability, making both countries better off. This indicates that if it were possible to dictate the timing of central banks' strategic choices, it would be desirable to force them to set inflation rates after security trading.

But if central banks cannot be jointly forced to set their policies after security trading, each would find it individually optimal to set inflation rates before trading, even if they had the possibility of setting policies discretionarily. To see this, consider a richer strategic setting in which central banks can either commit to state contingent inflation rates before trading takes place or set inflation rates discretionarily after trading has taken place. It is easy to verify that in the only subgame perfect Nash equilibrium both central banks will choose to use their commitment ability and set the inflation rates specified in Proposition 1 before trading takes place. In simpler terms, when central banks have the ability to commit to inflation rates before securities trading takes place, they would choose to do so rather than setting inflation rates discretionarily. This justifies our simplifying assumption that central banks never set inflation rates discretionarily.

\subsection{Deviating from symmetry}

We now want to briefly discuss if and how our results change when we move away from our symmetric setup. There are of course many different types of asymmetries; here we choose to focus on differences in country size. ${ }^{8}$ More specifically, we assume the West's population of young and of old increases to $1+\sigma$, without affecting per capita endowment, so that the representative young agent of the West still gets an endowment of $1+\alpha$ if $s=\omega$, and $1-\alpha$ if $s=\varepsilon .^{9}$ The maximization problems of the old representative agents of West and East - expressions (3) and (4) - are therefore unchanged. The market clearing condition (5), however, now looks different as a consequence of the West's greater population:

$$
x_{s}^{\mathrm{E}}=-(1+\sigma) x_{s}^{\mathrm{W}}, \quad s=\omega, \varepsilon .
$$

\footnotetext{
8 Appendix B discusses the differences in the probabilities of receiving a positive shock.

9 Note that this setup introduces aggregate uncertainty: when the larger country receives the positive shock (in state $\omega$ ) the aggregate endowment is greater than when the smaller country gets the positive shock (in state $\varepsilon$ ).
} 


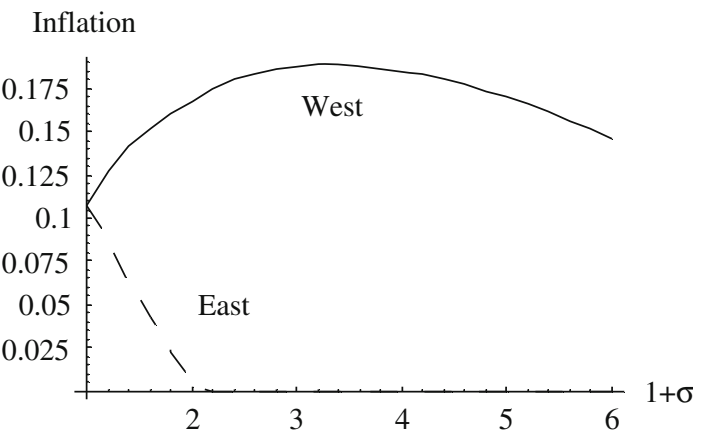

Fig. 1 Inflation

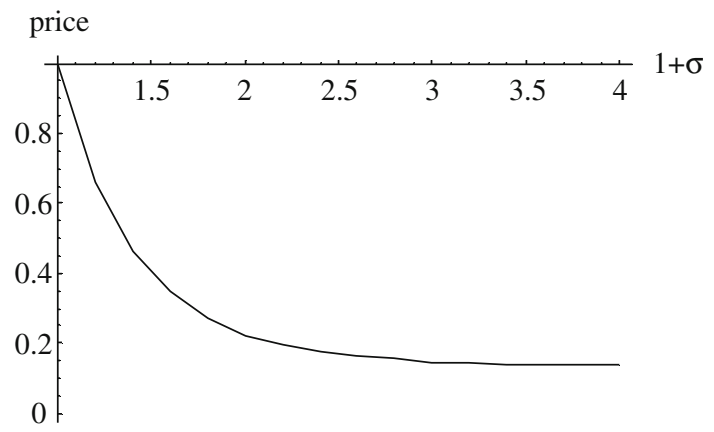

Fig. 2 Relative security price

This, in turn, affects the expression of the equilibrium price of securities (10):

$$
\widehat{p}=\left(\frac{(1+\alpha)(1+\sigma)\left(1-\delta \pi_{\omega}^{\mathrm{W}}\right)+(1-\alpha)}{(1+\alpha)\left(1-\delta \pi_{\varepsilon}^{\mathrm{E}}\right)+(1-\alpha)(1+\sigma)}\right)^{\rho} .
$$

The basic mechanism continues to apply. To improve the terms of trade of securities, each central bank may wish to commit to positive inflation in the state that is favorable to its country. However, these equilibrium inflation rates now differ across countries. As a result, the effects on the relative price of securities cease to cancel out. This implies that in equilibrium one of the two countries benefits from an improvement in its terms of trade. If this gain is enough to compensate for costly inflation, that country may actually end up better off than under price stability.

We now turn to a numerical example to illustrate these insights. We set $\delta=0.5$, and to make sure we get positive inflation in equilibrium, we choose $\rho=25$ and $\alpha=0.1$. Figure 1 plots the equilibrium levels of inflation in the West and the East as a function of the West's relative size. Figure 2 plots the relative price of securities: a ratio below 1 indicates an improvement in the West's terms of trade, compared to a situation without distortions. ${ }^{10}$ Figure 3 plots welfare in both countries: a positive value represents an improvement compared to price stability. ${ }^{11}$

\footnotetext{
${ }^{10}$ In other words, the relative price of securities in the absence of distortions has been normalized to 1 .

11 Welfare under price stability has been normalized to 0 .
} 


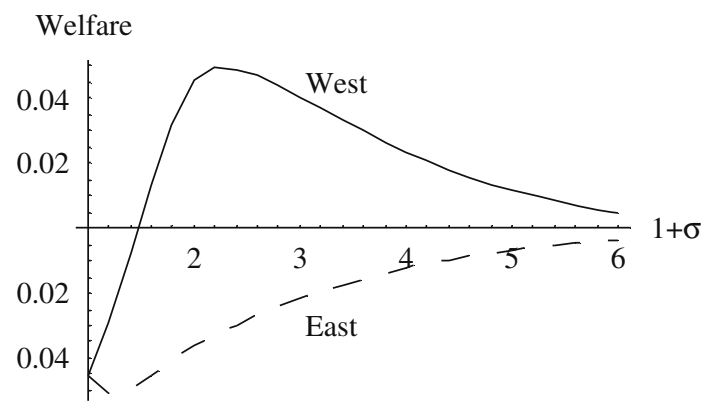

Fig. 3 Welfare

As can be seen in Figures 1, 2, and 3, increasing the relative size of the West initially leads to higher inflation, an improvement in its terms of trade, and greater welfare. However, as the size continues to increase, these results are partly reversed. There are two opposing forces at work. On the one hand, a given increase in inflation has a bigger effect on relative prices, the larger the relative size of the country. For a same marginal cost in terms of per capita endowment, the marginal benefit of inflation is bigger in the larger country. This means the West tends to distort more and benefit more as it grows in size. On the other hand, a same proportional shock in both countries implies a bigger absolute shock in the larger country. As a result, in state $s=\omega$ a positive shock in the West translates into a positive aggregate shock, and in state $s=\varepsilon$ a negative shock in the West leads to a negative aggregate shock. This reduces the scope for risk sharing, so that the West tends to distort less and benefit less as it grows in size. These opposing forces explain the non-monotone relations in Figures 1, 2, and 3.

The result we want to emphasize is that the larger country may be better off under the non-cooperative Nash equilibrium than under the benchmark of price stability. This happens for two reasons. First, larger countries find it easier to manipulate relative prices, and may wish to exploit this advantage. (This effect dominates in the upward sloping part of Figure 3.) Second, larger countries stand to gain less from efficient risk sharing, as country-specific shocks translate into aggregate shocks. (This effect dominates in the downward sloping part of Figure 3.) Note, however, that the increased welfare relative to price stability does not imply that there is no room for cooperation. In general, the non-cooperative Nash outcome continues to create excess inflation, so that monetary cooperation may still be Pareto improving. These issues will be further discussed in the next section.

\section{Monetary Cooperation}

As stated in Proposition 2, unilateral commitment by two separate central banks leads to an inefficient outcome. If countries are symmetric, positive inflation decreases welfare in both countries, without changing their terms of trade. In such an environment monetary cooperation may lead to a superior outcome. Cooperation can take on different forms. Separate central banks may continue to exist, with the difference that they now (explicitly or implicitly) coordinate their monetary 
policies. Or a common central bank may emerge that issues a common currency. We will mainly focus on the case of coordination between two separate central banks.

Under monetary coordination, each country's monetary policy rule is the negotiated outcome of a bargaining process. We assume that central banks have the same bargaining power, and therefore focus on the Nash bargaining solution of the game between the two central banks, each endowed with the preferences described in (11) and (12) and with threat points corresponding to the expected utility of the old in the equilibrium of the noncooperative game:

$$
\begin{aligned}
\widehat{\mathcal{W}} & =\mathcal{W}\left(\widehat{\pi}_{\omega}^{\mathrm{W}}, \widehat{\pi}_{\varepsilon}^{\mathrm{E}}\right), \\
\widehat{\mathcal{E}} & =\mathcal{E}\left(\widehat{\pi}_{\omega}^{\mathrm{W}}, \widehat{\pi}_{\varepsilon}^{\mathrm{E}}\right) .
\end{aligned}
$$

Proposition 3 If countries are symmetric, monetary cooperation leads to zero inflation in both states of nature.

\section{Proof See Appendix A.3.}

The intuition is straightforward. Given the symmetric setup, the solution must also be symmetric: in other words, it must satisfy the condition $\tilde{\pi}_{\omega}^{\mathrm{W}}=\tilde{\pi}_{\varepsilon}^{\mathrm{E}}$. Following (10), this implies that the relative price of securities remains unchanged (and equal to 1), independently of the level of inflation. Given that neither country benefits from an improvement in its terms of trade, it follows that the unique Pareto optimal solution is to have zero inflation in both states of nature.

We now discuss how our problem changes when we consider asymmetries between countries.

Proposition 4 If in the non-cooperative equilibrium inflation is strictly positive in both countries $\left(\widehat{\pi}_{\omega}^{W}>0\right.$ and $\left.\widehat{\pi}_{\varepsilon}^{E}>0\right)$, monetary cooperation between central banks allows for a Pareto superior outcome.

Proof See Appendix A.4.

The result is a simple consequence of the Pareto optimality and the individual rationality of the Nash bargaining solution, together with the inefficiency of the Nash equilibrium allocation of the non-cooperative game. To see the latter, notice that, when $\widehat{\pi}_{\omega}^{\mathrm{W}}>0$ and $\widehat{\pi}_{\varepsilon}^{\mathrm{E}}>0$, the equilibrium relative price $\widehat{p}$ is given by (18). Since both $\widehat{\pi}_{\omega}^{\mathrm{W}}$ and $\widehat{\pi}_{\varepsilon}^{\mathrm{E}}$ are strictly positive, it is clear that we can obtain the same relative price $\widehat{p}$ for lower values of inflation $\tilde{\pi}_{\omega}^{\mathrm{W}}$ and $\tilde{\pi}_{\varepsilon}^{\mathrm{E}}$, so that welfare improves in both countries. Cooperation can therefore lead to a Pareto superior outcome, compared to the non-cooperative solution, even when countries are not symmetric.

Going back to our numerical example of asymmetric country sizes, Figures 1 and 2 show that optimal inflation remains strictly positive in both countries as long as the West does not become too big, so that according to Proposition 4 it pays off to cooperate. However, if the West continues to grow in size, optimal inflation in the East goes to zero, but remains positive in the West. At that point the argument in our proof breaks down: we can no longer lower inflation in both countries, without changing the relative price of securities, because inflation in the smaller country is already zero. Under those circumstances monetary coordination would be unable to improve the welfare of the larger country, unless non-distortionary side payments were allowed. In that case monetary stability would always be optimal, since it 
maximizes aggregate consumption. It would then suffice to bargain over the size of the non-distortionary transfers to ensure that both parties gain.

Policy cooperation could also be achieved by adopting a common currency. A monetary union would make it feasible to commit to zero inflation for all states of nature, thus achieving an efficient outcome. In the symmetric case, the equilibrium allocation with zero inflation would Pareto dominate the equilibrium of the noncooperative game. When we deviate from symmetry, however, no such guarantee exists, and non-distortionary side payments may be necessary to ensure a Pareto superior outcome. As a more general point, note that the equilibrium allocation in a currency union would depend on the objective function and the policy restrictions of the common central bank. These institutional details themselves are likely to be the outcome of a bargaining process between national monetary and political authorities. A full treatment of the currency union therefore goes beyond the scope of this paper. However, as suggested before, it is possible to design a currency union in such a way to obtain an equilibrium allocation that Pareto dominates the equilibrium allocation of the non-cooperative game.

\section{Concluding Remarks}

In this paper we have shown that the ability of central banks to unilaterally commit to optimal contingent monetary policy rules is not sufficient to avoid excess inflation and to ensure efficient risk sharing. Even when expected inflation is equal to actual inflation, and even when actual inflation is costly, central banks may still find it beneficial to create price instability. In particular, the central bank of a given country may cause inflation, because it generates a cost that restrains the supply of securities of which its residents are net suppliers. By driving up the price of those securities, inflation may have a net beneficial effect on the country's welfare. In other words, the general equilibrium effects turn the cost of inflation into a benefit. If the direct welfare loss of inflation is more than compensated by the indirect welfare gain from an improvement in the terms of trade, a central bank may optimally choose to create inflation. As the central banks of both countries have the same incentives, the terms of trade effects may wash out, leading to an inefficient equilibrium allocation. To get rid of this externality problem, some form of monetary cooperation is necessary.

Our findings are reminiscent of Mundell (1961) who argued that countries facing asymmetric shocks should adopt a common currency because central banks may be tempted to inflate away their country's nominal payments, thus undermining efficient risk sharing. Our contribution is to clarify that monetary cooperation may still be needed even when agents trade in nominal indexed securities - whose real value cannot possibly be inflated away - and even when central banks are able to unilaterally commit to optimal contingent policy rules.

\section{Appendix A: Proofs of propositions}

\section{A.1 Proof of Proposition 1}

Part 1. The equilibrium is defined as a solution to (11) and (12), i.e., a combination of monetary policies $\left(\widehat{\pi}_{\omega}^{\mathrm{W}}, \widehat{\pi}_{\varepsilon}^{\mathrm{E}}\right)$, from which neither central bank has an incentive 
to deviate. Since the problem is perfectly symmetric, any solution must satisfy $\widehat{\pi}_{\omega}^{\mathrm{W}}=\widehat{\pi}_{\varepsilon}^{\mathrm{E}}$. Clearly, if $\widehat{\pi}_{\omega}^{\mathrm{W}}=\widehat{\pi}_{\varepsilon}^{\mathrm{E}}$, the equilibrium price will be $\widehat{p}=1$. Interior solutions are characterized by the following first order and second order conditions: $\partial \mathcal{W} / \partial \pi_{\omega}^{\mathrm{W}}=0, \partial^{2} \mathcal{W} / \partial\left(\pi_{\omega}^{\mathrm{W}}\right)^{2}<0, \partial \mathcal{E} / \partial \pi_{\varepsilon}^{\mathrm{E}}=0$, and $\partial^{2} \mathcal{E} / \partial\left(\pi_{\varepsilon}^{\mathrm{E}}\right)^{2}<0$. Corner solutions can arise in two cases: on the one hand, monetary policies $\left(\widehat{\pi}_{\omega}^{\mathrm{W}}, \widehat{\pi}_{\varepsilon}^{\mathrm{E}}\right)=$ $(0,0)$ constitute an equilibrium if at that point $\partial \mathcal{W} / \partial \pi_{\omega}^{\mathrm{W}}<0$ and $\partial \mathcal{E} / \partial \pi_{\varepsilon}^{\mathrm{E}}<0$; and on the other hand, monetary policies $\left(\widehat{\pi}_{\omega}^{\mathrm{W}}, \widehat{\pi}_{\varepsilon}^{\mathrm{E}}\right)=(1,1)$ form an equilibrium if at that point $\partial \mathcal{W} / \partial \pi_{\omega}^{\mathrm{W}}>0$ and $\partial \mathcal{E} / \partial \pi_{\varepsilon}^{\mathrm{E}}>0$. We now distinguish between the following cases:

1. Case 1: $\alpha \rho \geq 2$.

From the first order condition of maximization problem (11) and symmetry in equilibrium we have

$$
\begin{aligned}
\left.\frac{\partial \mathcal{W}\left(\pi_{\omega}^{\mathrm{W}}, \pi_{\varepsilon}^{\mathrm{E}}\right)}{\partial \pi_{\omega}^{\mathrm{W}}}\right|_{\left(\pi_{\omega}^{\mathrm{W}}=\pi_{\varepsilon}^{\mathrm{E}}\right)} & =\frac{x_{\omega}^{\mathrm{W}}}{\widehat{p}} \frac{\partial \widehat{p}\left(\pi_{\omega}^{\mathrm{W}}, \pi_{\varepsilon}^{\mathrm{E}}\right)}{\partial \pi_{\omega}^{\mathrm{W}}}-(1+\alpha) \delta \\
& =-2^{\rho-2}(1+\alpha) \delta \frac{4+(1+\alpha) \delta \widehat{\pi}_{\omega}^{\mathrm{W}}(\rho-2)-2 \alpha \rho}{\left(2-(1+\alpha) \delta \widehat{\pi}_{\omega}^{\mathrm{W}}\right)^{1+\rho}}=0 .
\end{aligned}
$$

Solving out for $\widehat{\pi}_{\omega}^{\mathrm{W}}$ gives us:

$$
\widehat{\pi}_{\omega}^{\mathrm{W}}=\frac{2 \alpha \rho-4}{(1+\alpha) \delta(\rho-2)} .
$$

Note that this solution is within the acceptable range: $0 \leq \widehat{\pi}_{\omega}^{\mathrm{W}} \leq 1 / \delta$. To check whether (21) corresponds to a local maximum, we check the second order condition:

$$
\left.\frac{\partial^{2} \mathcal{W}\left(\pi_{\omega}^{\mathrm{W}}, \pi_{\varepsilon}^{\mathrm{E}}\right)}{\partial\left(\pi_{\omega}^{\mathrm{W}}\right)^{2}}\right|_{\left(\pi_{\omega}^{\left.\mathrm{W}=\pi_{\varepsilon}^{\mathrm{E}}=\widehat{\pi}_{\omega}^{\mathrm{W}}\right)}\right.}<0 .
$$

Given that $\rho>2$, the second order condition holds. By symmetry

$$
\widehat{\pi}_{\varepsilon}^{\mathrm{E}}=\frac{2 \alpha \rho-4}{(1+\alpha) \delta(\rho-2)}
$$

and $\left(\widehat{\pi}_{\omega}^{\mathrm{W}}, \widehat{\pi}_{\varepsilon}^{\mathrm{E}}\right)$ satisfy the equilibrium conditions. It can easily be checked that there are no corner solutions.

2. Case 2: $\alpha \rho<2$ and $\rho>2$.

Taking the first order condition of maximization problem (11), and solving out for $\widehat{\pi}_{\omega}^{\mathrm{W}}$ gives us the same expression as in (21). Note, however, that in this case $\widehat{\pi}_{\omega}^{\mathrm{W}}<0$, so that the solution is outside the acceptable range. This leaves us with possible corner solutions. For monetary policies $\left(\pi_{\omega}^{\mathrm{W}}, \pi_{\varepsilon}^{\mathrm{E}}\right)=(0,0)$ we have:

$$
\frac{\partial \mathcal{W}(0,0)}{\partial \pi_{\omega}^{\mathrm{W}}}=-2^{\rho-2}(1+\alpha) \delta \frac{4-2 \alpha \rho}{2^{1+\rho}}<0 .
$$


By symmetry, $\partial \mathcal{E}(0,0) / \partial \pi_{\varepsilon}^{\mathrm{E}}<0$, so that monetary policies $\left(\widehat{\pi}_{\omega}^{\mathrm{W}}, \widehat{\pi}_{\varepsilon}^{\mathrm{E}}\right)=$ $(0,0)$ constitute an equilibrium. It can easily be checked that there do not exist other corner solutions.

3. Case 3: $\alpha \rho<2$ and $\rho \leq 2$.

Again, the first order condition of maximization problem (11) is given by (19). It is clear that the corresponding value $\widehat{\pi}_{\omega}^{\mathrm{W}}$ is outside the allowed range: if $\rho=2$, $\widehat{\pi}_{\omega}^{\mathrm{W}}$ would be minus infinity; if $\rho<2, \widehat{\pi}_{\omega}^{\mathrm{W}}=(2 \alpha \rho-4) /((1+\alpha) \delta(\rho-2))$, which is greater than $1 / \delta$. This again leaves us with possible corner solutions. By analogy with Case 2, it can easily be shown that monetary policies $\left(\widehat{\pi}_{\omega}^{\mathrm{W}}, \widehat{\pi}_{\varepsilon}^{\mathrm{E}}\right)=(0,0)$ constitute an equilibrium, and that there are no other corner solutions.

Part 2. Follows from straightforward calculations.

\section{A. 2 Proof of Proposition 2}

1. Given the problem is symmetric, we know that $\widehat{\pi}_{\omega}^{\mathrm{W}}=\widehat{\pi}_{\varepsilon}^{\mathrm{E}}$, so that according to (10) the equilibrium price $\widehat{p}=1$.

2. In state $s=\omega$ the aggregate endowment (of both countries together) net of inflation cost is $(1+\alpha)\left(1-\delta \widehat{\pi}_{\omega}^{\mathrm{W}}\right)+(1-\alpha)$; similarly, in state $s=\varepsilon$ the aggregate endowment net of inflation cost is $(1-\alpha)+(1+\alpha)\left(1-\delta \widehat{\pi}_{\varepsilon}^{\mathrm{E}}\right)$. Since $\widehat{\pi}_{\omega}^{\mathrm{W}}=\widehat{\pi}_{\varepsilon}^{\mathrm{E}}$, the aggregate endowment net of inflation is constant across states. This implies complete risk sharing; in each country consumption is fully smoothed across states. Given that countries are symmetric, each country will consume exactly half of the aggregate endowment net of inflation. Since $\alpha \delta>2$, inflation is strictly positive, so that consumption will be lower compared to the case of price stability.

\section{A.3 Proof of Proposition 3}

The Nash bargaining solution is given by

$$
\max _{\left(\pi_{\omega}^{\mathrm{W}}, \pi_{\varepsilon}^{\mathrm{E}}\right) \in[0,1 / \delta]^{2}}\left(\mathcal{W}\left(\pi_{\omega}^{\mathrm{W}}, \pi_{\varepsilon}^{\mathrm{E}}\right)-\widehat{\mathcal{W}}\right)\left(\mathcal{E}\left(\pi_{\omega}^{\mathrm{W}}, \pi_{\varepsilon}^{\mathrm{E}}\right)-\widehat{\mathcal{E}}\right) .
$$

Given symmetry, the first order conditions corresponding to the above maximization problem will also be symmetric, so that the equilibrium levels of inflation corresponding to the Nash bargaining solution will be identical: $\tilde{\pi}_{\omega}^{\mathrm{W}}=\tilde{\pi}_{\varepsilon}^{\mathrm{E}}$. This implies that the equilibrium relative price of securities will always be equal to 1 , independently of the level of inflation. Since inflation does not affect the relative price of securities, the maximization problem boils down to maximizing the endowment net of the inflation cost. Not surprisingly, this implies setting inflation equal to zero in both countries: $\tilde{\pi}_{\omega}^{W}=\tilde{\pi}_{\varepsilon}^{E}=0$.

\section{A.4 Proof of Proposition 4}

Given the Nash bargaining solution is Pareto optimal and individually rational it suffices to show that the Nash equilibrium of the non-cooperative game is inefficient. To see this notice that from (18) 


$$
\widehat{p}=\left(\frac{(1+\alpha)(1+\sigma)\left(1-\delta \widehat{\pi}_{\omega}^{\mathrm{W}}\right)+(1-\alpha)}{(1+\alpha)\left(1-\delta \widehat{\pi}_{\varepsilon}^{\mathrm{E}}\right)+(1-\alpha)(1+\sigma)}\right)^{\rho},
$$

where $\widehat{\pi}_{\omega}^{\mathrm{W}}>0$ and $\widehat{\pi}_{\varepsilon}^{\mathrm{E}}>0$. It is immediate to recognize that there are levels $\bar{\pi}_{\omega}^{\mathrm{W}}<\widehat{\pi}_{\omega}^{\mathrm{W}}$ and $\bar{\pi}_{\varepsilon}^{\mathrm{E}}<\widehat{\pi}_{\varepsilon}^{\mathrm{E}}$, that maintain the value of the relative price (25). If inflation is lower in both countries, and the relative price of securities is unchanged, welfare in both countries has increased.

\section{Appendix B: Inflation with asymmetric countries}

In this section we assume that state $\omega$ happens with probability $q$ and state $\varepsilon$ with probability $1-q$. Figure 4 plots the equilibrium inflation rates for West (when $s=\omega$ ) and East (when $s=\varepsilon$ ) in function of $q$. As can be seen, the lower the probability of receiving a positive shock, the higher the optimal inflation rate. The intuition is the following. Inflation leads to a drop in the endowment whenever the country experiences a positive shock. Therefore, the lower the probability of receiving a positive shock, the lower the expected cost of inflation, and the higher the optimal inflation rate. The different inflation rates in West and East lead to uncertainty in aggregate endowment net of inflation losses, so that risk sharing becomes incomplete: as soon as we deviate from $q=1 / 2$, there is less-than-full consumption smoothing in each country.

Moreover, the asymmetry implies that the terms of trade of one of the two countries may improve. Figure 5 illustrates this point: it plots $p$ in the non-cooperative outcome, relative to $p$ in the absence of inflation. If the ratio in Figure 5 rises above 1, East's terms of trade in securities improve; if the ratio drops below 1 , West's terms of trade improve. Figure 5 shows an improvement in West's terms of trade as $q$ drops below 1/2. This is consistent with our findings in Figure 4: for $q$ below $1 / 2$, inflation is higher in West than in East, so that the distortive capacity of West is greater than that of East.

Since the terms of trade of one of the two countries improves as we move away from $q=1 / 2$, that country may become better off compared to the benchmark case of price stability. Figure 6 confirms this argument by plotting the change

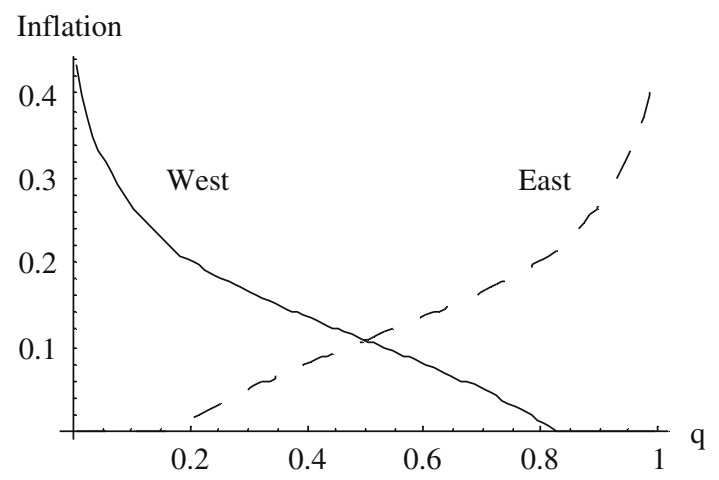

Fig. 4 Inflation 


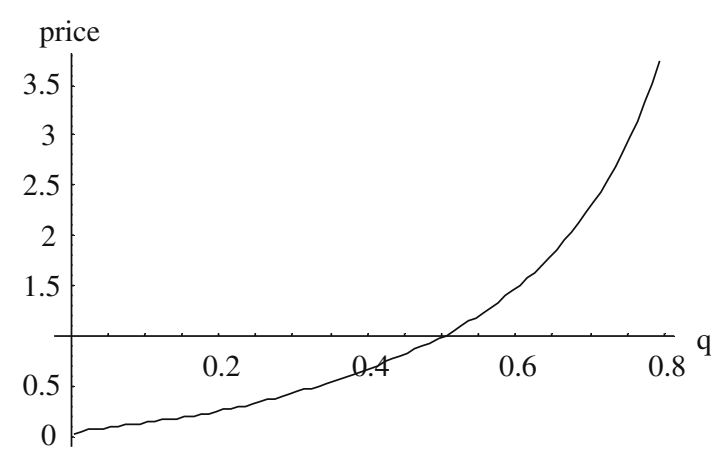

Fig. 5 Relative security price

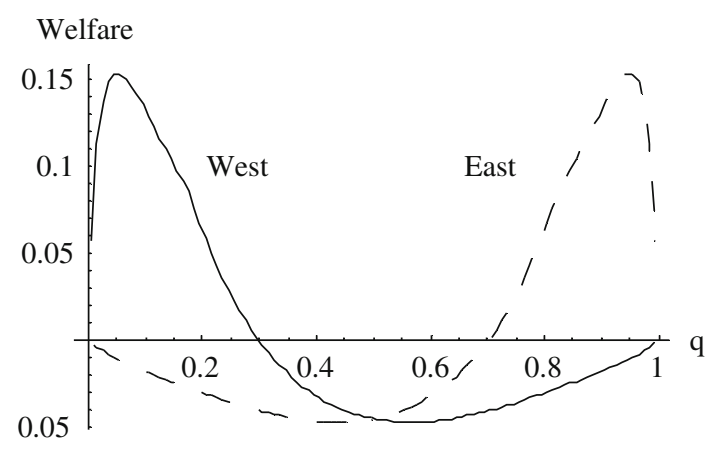

Fig. 6 Welfare

in West's welfare when moving from price stability to the non-cooperative Nash solution: for $q$ low enough, welfare improves. This is not surprising. As $q$ drops below $1 / 2$, West's terms of trade improve, whereas the cost of inflation falls. The non-monotone shape of the welfare change has to do with the degree of uncertainty: as $q$ approaches 0 or 1 , uncertainty becomes very small, so that the gains from risk sharing - and the gains from distorting - become negligible. Our results therefore suggest that the country experiencing positive shocks with a low probability may have less to gain from monetary cooperation.

\section{References}

Alesina, A., Barro, R.J.: Currency unions. Q J Econ 117(2), 409-436 (2002)

Barro, R.J., Gordon, D.B.: Rules, discretion and reputation in a model of monetary policy. J Monetary Econ 12(1), 101-21 (1983a)

Barro, R.J., Gordon, D.B.: A positive theory of monetary policy in a natural-rate model. J Polit Econ 91(4), 589-610 (1983b)

Celentani, M., Conde-Ruiz, J.I., Desmet, K.: Endogenous policy leads to inefficient risk sharing. Rev Econ Dyn 7, 258-787 (2004)

Ching, S., Devereux, M.B.: Risk Sharing and the theory of optimal currency areas: a re-examination of Mundell 1973. HKIMR Working Paper 8/2000 (2000)

Ching, S., Devereux, M.B.: Mundell revisited: a simple approach to the costs and benefits of a single currency area. Rev Int Econ 11(4), 674-691 (2003) 
Cooley, T.F., Hansen G.: The inflation tax in a real business cycle model. Am Econ Rev 79, 733-748 (1989)

Cooley, T.F., Quadrini, V.: Common currencies vs. monetary independence. Rev Econ Stud 70, 807-824 (2003)

Corsetti, G., Pesenti, P.: Welfare and macroeconomic interdependence. Q J Econ 116, 421-445 (2001)

Ferraris, L.: On the complementarity of money and credit, mimeo. Madrid: Universidad Carlos III 2005

Gillman, M.: The welfare cost of inflation in a cash-in-advance economy with costly credit. J Monetary Econ 31, 97-115 (1993)

Kurz, M.: On the structure and diversity of rational beliefs. Econ Theory 4, 877-900 (1994)

Kurz, M., Jin, H., Motolese, M.: The role of expectations in Economic fluctuations and the efficacy of monetary policy. Working Paper 03-010, Department of Economics, Stanford University (2003)

Magill, M., Quinzii, M.: Theory of incomplete markets, Vol. 1. Cambridge, MA.: MIT Press 1996

McKinnon, R.I.: Optimum currency areas and the European experience. EconTransit 10(2) (2002)

Mundell, R.: A theory of optimum currency areas. American Econ Rev 51, 509-517 (1961)

Mundell, R.: Uncommon arguments for common currencies. In: Johnson, H.G., Swoboda, A.K. (eds.) The economics of common currencies. London: Allent \& Unwin 1973 